\title{
Biological Control of Fungal Plant Pathogen Penicillium digitatum Causing Green Rot of Citrus Fruit by Local Trichoderma Isolates from Bihar, India
}

\author{
Md. Irshad Hussain* \\ Plant Pathology \& Microbiology Lab, Department of Botany, Patna University, \\ Patna-5, Bihar, India \\ *Corresponding author
}

\section{A B S T R A C T}

The current research reveals the biocontrol potential of local Trichoderma isolates against the fungal pathogen Penicillium digitatum which causes green rot of Citrus fruit. In the present investigation, the isolates of Trichoderma spp. grown from locally collected soil samples were screened against the fungal pathogen Penicillium digitatum, which resulted into the substantial inhibition of the fungal phytopathogen. The soil samples collected from various local rhizosphere of Bihar state in India were inoculated on various nutritive media especially the Trichoderma Specific Media (TSM) and Potato Dextrose Agar (PDA) media using the serial dilution technique. Altogether 11 different Trichoderma spp. were isolated. These isolates were identified using authentic manual of fungi for morphological and

\section{Keywords}

Antagonistic capability, Biopriming In vivo

efficacy, Phytopathogen, Penicillium,

Trichoderrma etc.

Article Info

Accepted:

23 March 2018

Available Online:

10 April 2018 microscopic identification and further identification was done based on molecular techniques using D1/D2 region of LSU (Large SubUnit:28S rDNA). The pathogen Penicillium digitatum was isolated from rotten citrus fruits and were confirmed by its microscopic identification. The antagonistic capability of Trichoderma isolates was checked by screening it against the fungal phytopathogen using three antagonistic techniques namely Dual culture, Culture Filtrate Assay and Slide culture Assay. The isolates of Trichoderma spp. (TH-5) and (TA-7) having a higher antagonistic potential among all the isolates of Trichoderma, at optimum temperature were selected for In vitro screening against the fungal pathogen Penicillium digitatum. In the dual culture technique, the isolate $T H-5$ showed $76.9 \%$ growth inhibition while the isolate $T A-7$ showed $78.8 \%$ growth inhibition against $P$. digitatum. The cell free culture filtrate which was extracted from Trichoderma isolates were screened at three different concentrations i.e., 20\%, 40\% and $60 \%$ against the fungal phytopathogen. The screening of culture filtrate against the fungal pathogen also shows significant inhibition of radial growth especially at $40 \%$ and $60 \%$ concentration. The maximum inhibition was recorded for $T H-5$ and TA-7 isolates. Similarly, the $T H-5$ and $T A-7$ isolates were grown with both fungal pathogens on slide culture and the growth of mycelia was measured. The impact of slide culture method was marked as reduced mycelial growth of the fungal pathogen Penicillium digitatum. These In Vitro tests revealed the biocontrol potential of Trichoderma isolates against Penicillium digitatum, confirming the capability of the local Trichoderma isolates in the biological control of the fungal pathogen Penicillium digitatum. 


\section{Introduction}

Penicillium digitatum is the potent fungal plant pathogen causing various post-harvest in various citrus fruits. Apart from the plant diseases, many strains of Penicillium digitatum produce significant quantities of toxic compounds known as mycotoxins, which are toxic to immunocompromised individuals. Along with it, Penicillium digitatum is implicated in human disease notably in the mycosis and in some reporting of pneumonia in humans. The Penicillium digitatum is responsible for $90 \%$ of citrus fruits lost to infection after harvesting and considered the largest cause of post-harvest disease occurring in Californian citrus fruits (Ariza, 2002). Its widespread impact relates to the post-harvest disease it causes in citrus fruits known as green rot or mould (Brown, 1995). The post-harvest losses of citrus fruits due to the green rot caused by Penicillium digitatum leads to the nutritional imbalance, as these fruits are the essential part of a balanced diet for human beings. In these food items, apart from the basic building blocks like proteins, carbohydrates, fats etc., these provide a lot of enzymes, nutrients and antioxidants, which is helpful in many metabolic processes inside the cell. This reduction in the yield of the natural food items up to a considerable extent is caused by the most prominent fungal phytopathogen Penicillium digitatum.

Traditionally, certain inorganic fertilizers are used to overcome the infestation caused by the fungal phytopathogens which ultimately influences both yield and its quality (Anonymous, 2002). But, in recent times, the biological control of diseases is given priority over chemical sprays which are based on the natural antagonists and its by products. Now a day, the efforts are being made to explore the biocontrol potential of local microbial inoculants as bio-control agents, being effective and attractive alternatives to chemical fungicides. The Trichoderma spp. has been widely studied as potential biocontrol agents for controlling many plant pathogens (Agrios, 2005; Lynch, 1994). Most of the studies on Trichoderma species have been conducted with respect to their activity as biological control agents against fungal pathogens (Papavizas, 1992, Sahebani and Hadavi, 2008, Hanada, 2009).

The present study was carried out to check the antagonistic capability of selected isolates of Trichoderma, isolated from local soil samples of Bihar against the fungal pathogen Penicillium digitatum. This work explores the antagonistic capability of local isolates of Trichoderma spp. for their use as a biocontrol agent as well as the promising part of Integrated crop improvement and Integrated pest management (IPM).

\section{Materials and Methods}

\section{Isolation of Trichoderma isolates}

The Trichoderma spp. were isolated from the local soil rhizosphere of various native areas of Bihar. The soil samples were collected and different concentrations of it was prepared using serial dilution technique which was poured on various nutritive media especially Trichoderma specific medium (TSH) and Potato Dextrose Agar media (PDA) (Askew and Laing 1993). The mix culture was developed on the media plate due to presence of many soil borne fungi in the soil sample which was further inoculated for their pure culture. After repeated pure culture technique, altogether 11 isolates of Trichoderma spp. were identified using authentic manual of fungi along with the identification based on molecular techniques using D1/D2 region of LSU (Large SubUnit: 28S rDNA). The pure culture of the selected isolates was further maintained on PDA medium. 


\section{Isolation of Penicillium digitatum}

The fungal phytopathogen Penicillium digitatum was isolated from the rotten citrus fruit which was affected by a number of fungal phytopathogens. The samples were collected from local markets which were carried to the laboratory for further investigation. The fungal phytopathogen Penicillium digitatum was inoculated on Czapek Yeast Extract Agar medium and Potato Dextrose Agar (PDA) media and the process was continued followed by sterilization and culturing of inoculants. Finally, the fungal phytopathogen Penicillium digitatum was isolated after identification using authentic manual of fungi. These isolated pathogens were further maintained for its pure culture on Potato Dextrose Agar (PDA) medium at $4^{\circ} \mathrm{C}$.

\section{In vitro screening for antagonistic activities of the Biocontrol agents}

The isolates of Trichoderma antagonists were screened against the prominent fungal phytopathogen Penicillium digitatum which resulted into the reduced mycelial growth of the fungal phytopathogen. In this investigation, the test antagonists were carried out on PDA medium using dual culture technique. The experiment was laid down with three treatments and their three replicates. The treatments were made by two bio-agents versus the pathogen and the third was the control. In control experiment, the test antagonist was replaced by sterile agar disc. In this process, the two different assessments were made following the dual culture techniques. The first was to obtain the percentage inhibition of radial growth (PIRG) of the fungal phytopathogen Penicillium digitatum and secondly the number of days taken for Trichoderma isolates to totally overgrow onto the fungal phytopathogen Penicillium digitatum.

\section{First assessment}

In this assessment, five millimeter diameter mycelia disc of each test antagonist was paired against the fungal phytopathogen Penicillium digitatum on PDA contained in $90 \mathrm{~mm}$ diameter Petri dishes following method of Evans et al., (2003). Five millimeter plugs of each of the Bioagents were placed at $20 \mathrm{~mm}$ away from the edge of Petri dish and after 24 $\mathrm{h}$ of incubation, the fungal phytopathogen Penicillium digitatum was placed at $20 \mathrm{~mm}$ away from other edge of the same Petri dish. The set up was incubated at $28+2^{\circ} \mathrm{C}$ for ten days enquire. The growth of the pathogen in both the test and control experiments were recorded. Data was collected for the percentage inhibition of radial growth (PIRG) $=\left(R_{1}-R_{2}\right) / R_{1} \times 100$. When $R_{1}=$ Radial growth of fungal pathogen in control, $\mathrm{R}_{2}=$ Radial growth of fungal pathogen in dual culture experiment with antagonist.

\section{Second assessment}

The number of days taken by Trichoderma isolates to completely overlap the prominent fungal phytopathogen colony was recorded. The antagonist taking the least number of days to completely overcome the fungal phytopathogen was counted for signifying its good antagonistic capability.

\section{Culture filtrate assay}

In this type of antagonistic screening, the culture filtrate of the antagonists was extracted with the help of liquid media and was used for reducing the mycelia growth of the fungal phytopathogen. In this experiment, $100 \mathrm{ml}$ of Potato Dextrose Broth (PDB) were dispensed into $250 \mathrm{ml}$ - Erlenmeyer flasks and inoculated with $5 \mathrm{~mm}$ diameter disc from edge of 7 days old culture of the three test antagonists already maintained on PDA. Each flask was inoculated with three discs of each in triplicate 
and set up was inoculated at $28+2^{\circ} \mathrm{C}$ for 15 days. (The liquid media prepared was kept on mechanical shaker to maintain homogenous growth). After optimum incubation, the cultures were filtered through Whatman No. 1 filter paper and stored at $4^{\circ} \mathrm{C}$ for further use. The sterilized filtrate was amended in PDA to make three concentrations $(20 \% \quad 40 \%$ and $60 \%$ ) in petri plates. The solidified agar plates in triplicates were inoculated at the centre with $5 \mathrm{~mm}$ diameter mycelial disc of test fungal phytopathogen and inoculated at optimum temperature for 7 days. The plates devoid of culture filtrate served as control. The radial growth of fungal phytopathogen Penicillium digitatum was measured in presence of different concentrations of the culture filtrates to check the antagonistic capability of the Trichoderma isolates.

\section{Results and Discussion}

\section{Identification of isolates of Trichoderma spp}

Initially, the colonies of Trichoderma spp. grown on agar medium were white in color which then enlarged to 5-6 $\mathrm{mm}$ within 5-6 days. The white colony then turned off white yellowish and finally turned greenish on Trichoderma Specific Medium (TSM) (Figure 4) which was aided in their identification from other soil borne fungi. The two methods used to identify the colonies i.e. visual observations on petridishes and micro-morphological studies in slide culture were adopted for identification of Trichoderma species (Table $1)$.

Genomic DNA isolation, amplification of $18 S$ region of $\mathrm{SSU}$ gene of $\mathrm{DNA}$ and sequencing

The isolate TA-7 was also identified by molecular identification in which the genomic DNA of Trichoderma atroviride (TA-7) was extracted by Xcelris genomics. The DNA was isolated from the culture isolated from soil samples. Its quality was evaluated on $1.2 \%$ Agarose Gel, a single band of high-molecular weight DNA was observed. The fragment of $18 \mathrm{~S}$ region of SSU gene was amplified by PCR from the above isolated plasmid DNA. A single discrete PCR amplicon band of $900 \mathrm{bp}$ was observed when resolved on Agarose Gel (Gel Image-1). The PCR amplicon was purified to remove the contaminants. The forward and reverse DNA sequencing reaction of PCR amplicon was carried out with $1 \mathrm{~F}$ and 4R primers using BDT v3.1 Cycle sequencing kit on ABI 3730xl Genetic Analyzer. The consensus sequence of 838 bp of $18 \mathrm{~S}$ region was generated from forward and reverse sequence data using aligner software. Finally, the $18 \mathrm{~S}$ region of SSU gene sequence was used to carry out BLAST with the database of NCBI gene bank database. Based on maximum identity score first ten sequences were selected for the phylogenetic tree which was constructed using MEGA 4.

The cultures of Trichoderma spp. were found to be $T$. harzianum, $T$. atroviride and other species of Trichoderma based on their shape, size, arrangement and development of conidiophores or phialides etc. which provided a tentative basis for identification. These samples were compared to a taxonomic key by Rifai MA C 1969). T. atroviride was identified based on nucleotide homology and phylogenetic analysis (Fig. 1 and 2).

\section{PIRG and colony overgrowth assessment}

The isolates of Trichoderma viz; T harzianum, $T$. viride and $T$ atroviride inhibited the mycelial growth of fungal phytopathogen Penicillium digitatum at different degree of inhibition. The PIRG by these Trichoderma isolates ranged from minimum $63.9 \%$ to maximum $78.8 \%$. The highest PIRG value recorded was that of $T A-7$ followed by $T H-5$ (Table 2, Fig. 3). 
Table.1 Identification of Trichoderma isolates from local soil samples

\begin{tabular}{|c|c|c|}
\hline Sl. No. & Trichoderma isolates & Identified isolates \\
\hline 1 & $T H-3, T H-5, T H-6, T H-10$ & $T$. harzianum \\
\hline 2 & $T V-1, T V-2$ & $T$. viride \\
\hline 3 & $T A-7, T A-9, T A-11$ & $T$. atroviride \\
\hline 4 & $T-4, T-8$ & Unknown spp. \\
\hline
\end{tabular}

Table.2 Showing antagonistic potential of Trichoderma isolates against Penicillium digitatum in dual culture technique

\begin{tabular}{|c|c|c|c|c|}
\hline SI. No. & Trichoderma isolates & $\begin{array}{c}\text { Radial growth } \\
(\mathbf{c m})\end{array}$ & $\begin{array}{c}\text { \% inhibition of radial } \\
\text { growth (PIRG) }\end{array}$ & $\begin{array}{c}\text { Time of overgrowth } \\
\text { (days) }\end{array}$ \\
\hline $\mathbf{1 .}$ & $T V-1$ & 3.0 & 71.6 & 8 \\
\hline $\mathbf{2 .}$ & $T V-2$ & 3.12 & 69.3 & 8 \\
\hline $\mathbf{3 .}$ & $T H-3$ & 2.96 & 67.1 & 9 \\
\hline $\mathbf{4 .}$ & $T-4$ & 3.35 & 69.7 & 7 \\
\hline $\mathbf{5 .}$ & $T H-5$ & 2.07 & 79.9 & 7 \\
\hline $\mathbf{6 .}$ & $T H-6$ & 3.41 & 64.1 & 7 \\
\hline $\mathbf{7 .}$ & $T A-7$ & 1.90 & 78.8 & 8 \\
\hline $\mathbf{8 .}$ & $T-8$ & 3.15 & 68.0 & 9 \\
\hline $\mathbf{9 .}$ & $T A-9$ & 3.44 & 63.9 & 7 \\
\hline $\mathbf{1 0 .}$ & $T H-10$ & 3.19 & 67.5 & - \\
\hline $\mathbf{1 1 .}$ & $T A-11$ & 3.12 & 65.9 & \\
\hline $\mathbf{1 2 .}$ & Control (Fungal & 9.00 & 0.0 & \\
\hline
\end{tabular}

Table.3 Effect of different concentrations (20\%, $40 \%$ and $60 \%)$ of culture filtrates of

Trichoderma isolates on the growth of the fungal phytopathogen Penicillium digitatum

\begin{tabular}{|c|c|c|c|c|c|c|}
\hline \multirow[b]{3}{*}{$\begin{array}{c}\text { Trichoderma } \\
\text { isolates }\end{array}$} & \multicolumn{6}{|c|}{ Penicillium digitatum } \\
\hline & \multicolumn{2}{|c|}{$20 \%$} & \multicolumn{2}{|c|}{$40 \%$} & \multicolumn{2}{|c|}{$60 \%$} \\
\hline & $\begin{array}{c}\text { Average } \\
\text { growth } \\
(\mathbf{m m})\end{array}$ & $\begin{array}{c}\text { Percent \% } \\
\text { inhibition } \\
\text { over } \\
\text { control }\end{array}$ & $\begin{array}{c}\text { Average } \\
\text { growth } \\
(\mathbf{m m})\end{array}$ & $\begin{array}{c}\text { Percent \% } \\
\text { inhibition } \\
\text { over } \\
\text { control }\end{array}$ & $\begin{array}{c}\text { Average } \\
\text { Growth } \\
\text { (mm) }\end{array}$ & $\begin{array}{c}\text { Percent \% } \\
\text { inhibition } \\
\text { over } \\
\text { control }\end{array}$ \\
\hline$T V-1$ & 80.3 & $10.7 \%$ & 49.1 & $45.4 \%$ & 29.1 & $67.6 \%$ \\
\hline$T V-2$ & 77.3 & $14.1 \%$ & 45.5 & $49.4 \%$ & 28.8 & $68.0 \%$ \\
\hline$T H-3$ & 79.1 & $12.1 \%$ & 50.5 & $43.8 \%$ & 30.1 & $66.5 \%$ \\
\hline$T-4$ & 78.4 & $12.8 \%$ & 51.2 & $43.1 \%$ & 32.4 & $64.0 \%$ \\
\hline TH -5 & 75.4 & $16.2 \%$ & 43.1 & $52.1 \%$ & 25.4 & $71.7 \%$ \\
\hline TH-6 & 79.0 & $12.2 \%$ & 52.0 & $42.2 \%$ & 31.7 & $64.7 \%$ \\
\hline$T A-7$ & 74.1 & $17.6 \%$ & 42.8 & $52.4 \%$ & 24.4 & $72.8 \%$ \\
\hline$T-8$ & 80.5 & $10.5 \%$ & 51.3 & $43.0 \%$ & 29.5 & $67.2 \%$ \\
\hline TA-9 & 81.0 & $10.0 \%$ & 53.5 & $40.5 \%$ & 30.0 & $66.6 \%$ \\
\hline TH-10 & 78.8 & $12.4 \%$ & 55.9 & $37.8 \%$ & 29.4 & $67.3 \%$ \\
\hline$T A-11$ & 81.8 & $9.1 \%$ & 52.8 & $41.3 \%$ & 32.3 & $64.1 \%$ \\
\hline CONTROL & 90.0 & 0.0 & 90.0 & 0.0 & 90.0 & 0.0 \\
\hline
\end{tabular}




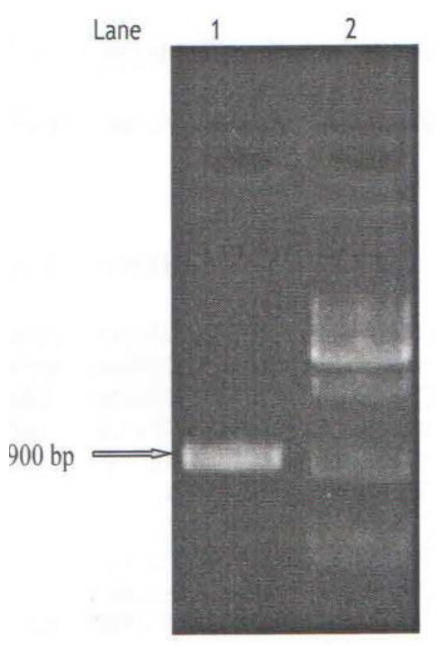

[Gel Image 1]

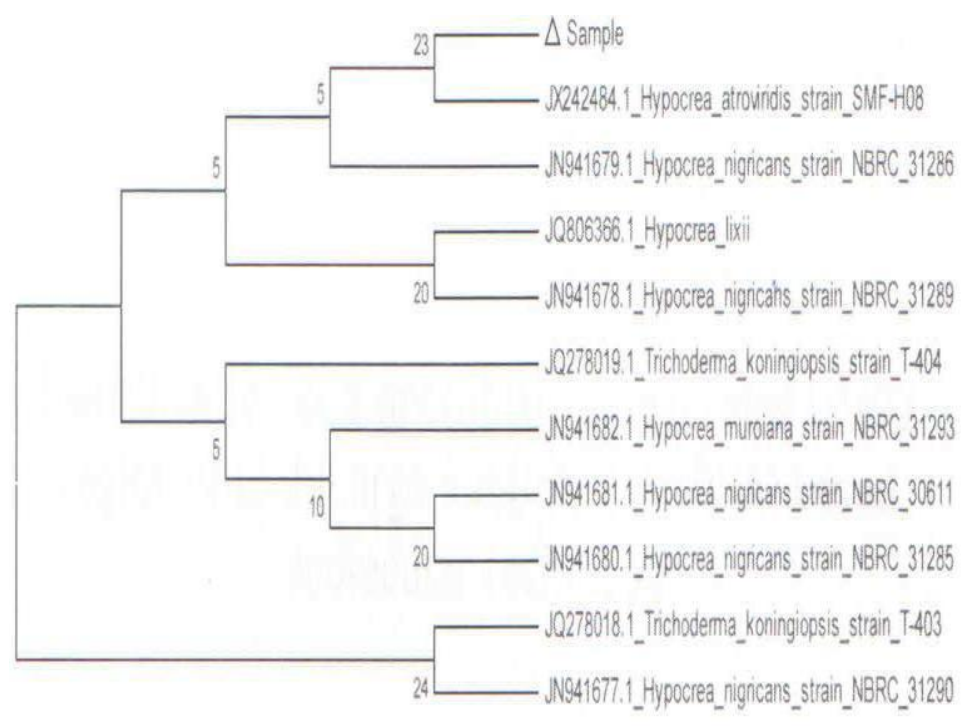

Figure 1: Lane 1: $18 \mathrm{~S}$ region of SSU amplicon band, Lane 2: DNA marker

Figure 2: Phylogenetic tree of the Identification of Trichoderma atroviride

Fig.3 Percentage inhibition of radial growth (PIRG) of mycelia of the fungal phytopathogen Penicillium digitatum due to the isolates of Trichoderma spp.

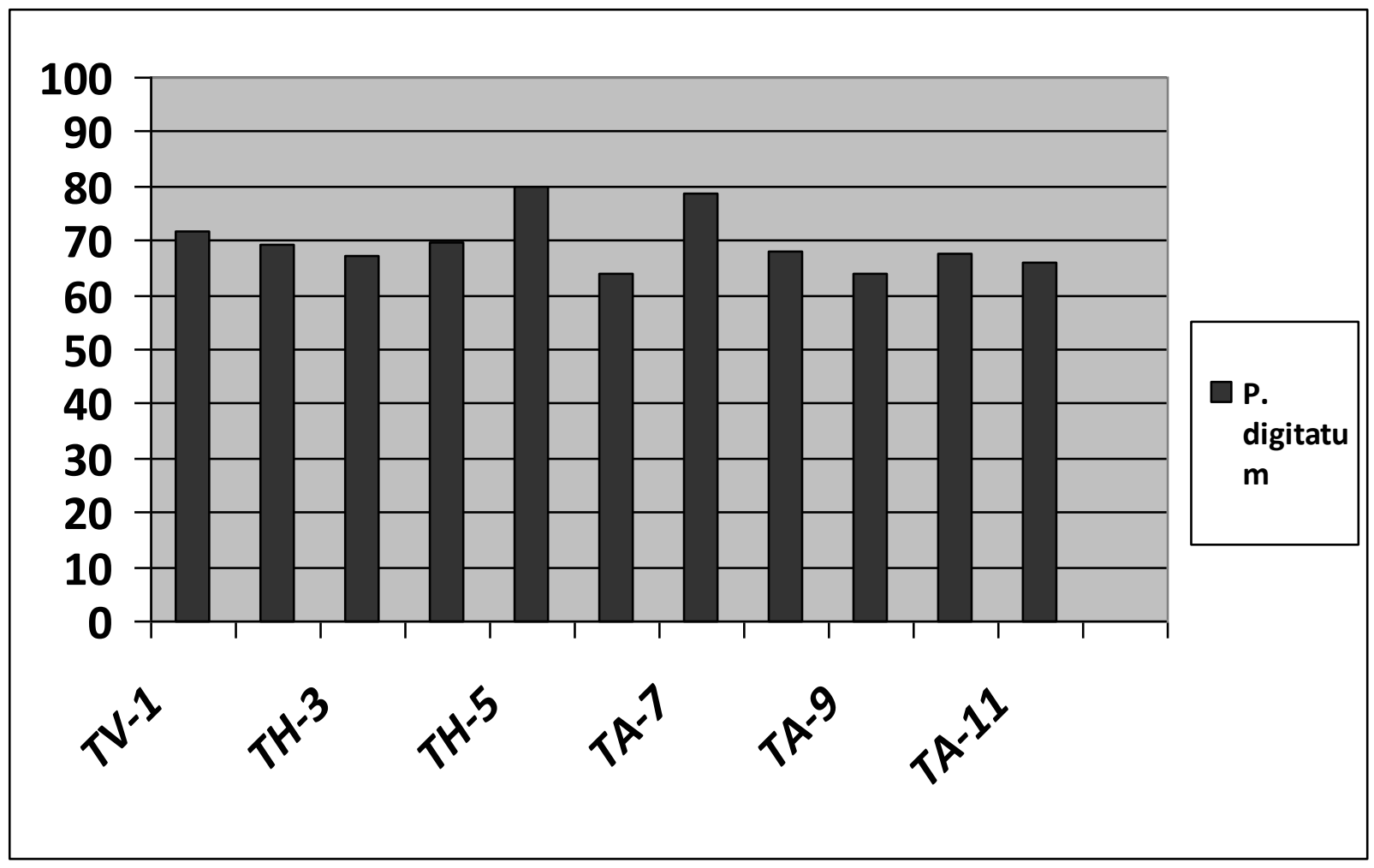


Fig.4 Cultural characteristics of Penicillium digitatum front view (A), Penicillium digitatum back view (B), Microscopic view of Penicillium digitatum (C) Trichoderma isolate (D), Different dual culture plates (E), Microscopic view of Trichoderma isolate (F), Antagonistic effect of

Trichoderma isolate $(\mathrm{G})$ and culture filtrates of Trichoderma isolates $(\mathrm{H})$
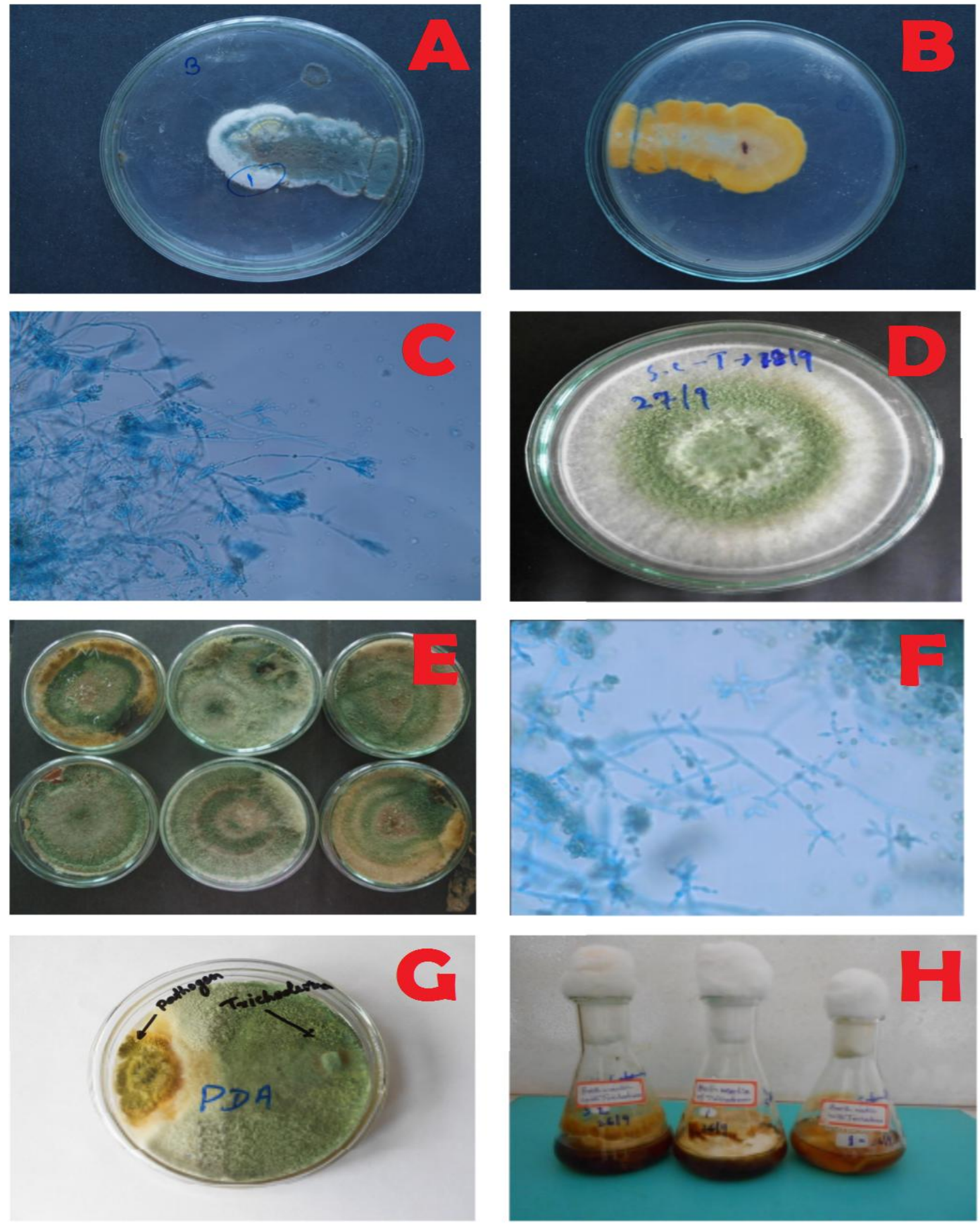
The time required by the Trichoderrma isolates to overgrow the fungal pathogen colony fully was recorded and was minimum of 7 days for the isolates $T H-5$ and TA-7 after incubation whereas it was higher (up to 10 days) for other isolates of Trichoderma spp.

Thus, according to both the assessments, the Trichoderma isolates revealed their best antagonistic potential against the fungal phytopathogen Penicillium digitatum. In this assessment, the two isolates $T H-5$ and TA-7 showed the maximum antagonistic potential as compared to the other isolates of Trichoderma spp.

The $60 \%$ concentration culture filtrate of the Trichoderma isolates undertaken, almost completely inhibited the radial growth of tested pathogen, but $20 \%$ and $40 \%$ dilution had varying effect, as mentioned in Table 3. Hence, the results obtained from the In Vitro study, showed that the native isolates of Trichoderma spp. can be used effectively against the soil borne fungal phytopathogen Penicillium digitatum. The fast mycelial growth of Trichoderma isolates also adds to its ability having a better antagonistic potential.

The results indicated that the isolates of Trichoderma spp. are effective in the In Vitro conditions against the selected fungal phytopathogen Penicillium digitatum. The dual culture technique as well as culture filtrate assay has proved the antagonistic capability of the locally isolated Trichoderma isolates against the fungal phytopathogen Penicillium digitatum. The present findings are in consistent with the earlier findings (Mishra et al., 2011) showing the potential of biological control on specific plant pathogen Penicillium digitatum and express the capability of local Trichoderma isolates to be effective in various In Vitro conditions against the fungal phytopathogen.

\section{References}

Agrios, G. N. (2005). Plant Pathology. $5^{\text {th }}$ ed. Academic Press, INC. Pp903.

Anonymous, (2002). Vegetables 2001: Summary Agricultural Statistics Board. National Agricultural Statistics Service, USA.

Ariza, Marta R., Larsen, Thomas O., Duus, Jens O., Barrero, Alejandro F. (2002). "Penicillium digitatum Metabolites on Synthetic Media and Citrus Fruits". Journal of Agricultural and Food Chemistry. 50 (22): 6361-6365.

Askew D.J., Laing M.D. (1993). An adapted selective medium for the quantitative isolation of Trichoderma Species. Plant Pathology 42: 686-690.

Brown, G. Eldon. (1995) "Citrus DiseasesPost Harvest". University of Florida: IFAS Indian River Research and Education Center. University of Florida.

Hanada, R.E., De Souza, J.T., Pomella, A.W.V., Hebbar, K.P., Pereira, J.O., Ismaiel, A., Samuels, G.J., (2008). Trichoderma martiale sp. nov., a new endophyte from sapwood of Theobroma cacao and a potential agent of biological control. Mycological Research 112, 1335-1343.

Joshi, B.B., Bhatt, R.P. and Bahukhandi, D. (2010). Antagonistic and plant growth activity of Trichoderma isolates of Western Himalayas. J. Environ. Bio, 31(6): 921-928.

Lynch, J. M. Fungi antagonists. In: R. R. Baker, P. E. DUNN (eds.) (1990). New directions in biological control: Alternatives for suppressing agricultural pests and disease, 243-253. Alan $R$. Liss, New York.

McLean, K.L., Swaminathan, J., Frampton, C.M., Hunt, J.S., Ridgway, H.J and Stewart, A. (2005). Effect of formulation on the rhizosphere competence and biocontrol ability of 
Trichoderma atroviride C52. Plant Pathol, 54: 212- 218.

Mishra, B.K., Mishra, R.K., Mishra, R.C., Tiwari, A.K., Yadav, R.S. and Dikshit, A. (2011). Biocontrol efficacy of isolates Trichoderma viride against fungal plant pathogens causing disease in Vigna radiate L. Arch. Appl. Sci. Res.,3(2): 361-369.

Ousley M.A., Lynch J.M., Whipps J.M., (1994). Scientia Horticulture, 59:147155.

Papavizas, G. C. (1992). Biological control of selected soil borne plant pathogens with Trichoderma and Gliocadium. In: TJAMOS, E. C., Papavizas, G. C., Cook, R. J. (eds): Biological control of plant diseases - Progress and challenges for future. 223- 241. Plenum Press-New York.

Prasad, R.D., Rangeshwaran, R., Anuroop, C.P. and Rashni, H.J. (2002). Biological control of wilt and root rot of chickpea under field conditions. Ann. Pl. Prot. Sci., 10 (1): 72-75.

Rifai, M.A. (1969). A revision of the genus Trichoderma. Mycol Pap, 116: 1-116.

Sahebani N, Hadavi N. (2008). Biological control of the root-knot nematode Meloidogyne javanica by Trichoderma harzianum. Soil Biol. Biochem., 40: 2016-2020.

Tjamos C., Papavizas G.C., Cook R.J., eds. (1992). Biological Control of Plant Diseases: Progress and Challenges for the Future. Adv. Res. Works. New York: Plenum.

\section{How to cite this article:}

Md. Irshad Hussain. 2018. Biological Control of Fungal Plant Pathogen Penicillium digitatum Causing Green Rot of Citrus Fruit by Local Trichoderma Isolates from Bihar, India. Int.J.Curr.Microbiol.App.Sci. 7(04): 2970-2978. doi: https://doi.org/10.20546/ijcmas.2018.704.337 